\title{
Treatment Result in the Initial Stage of Kanazawa Mobile Embolectomy Team for Acute Ischemic Stroke
}

\author{
Naoyuki UCHIYAMA, ${ }^{1}$ Kouichi MISAKI, ${ }^{1}$ Masanao MOHRI, ${ }^{1}$ Tomoya KAMIDE, ${ }^{1}$ \\ Yuichi HiROTA, ${ }^{2}$ Ryo HigASHI, ${ }^{3}$ Hisato MinAmIDE, ${ }^{4}$ Yukihiko KOHDA, ${ }^{5}$ \\ Takashi ASAHI, ${ }^{6}$ Katsuo SHOIN, ${ }^{7}$ Masayuki IwATO, ${ }^{8}$ Daisuke KITA, ${ }^{9}$ \\ Yoshitaka HAMADA, ${ }^{10}$ Yuya YOSHIDA, ${ }^{11}$ and Mitsutoshi NAKADA ${ }^{1}$
}

\begin{abstract}
${ }^{1}$ Department of Neurosurgery, Kanazawa University Hospital, Kanazawa, Ishikawa, Japan; ${ }^{2}$ Department of Neurosurgery, Kanazawa Municipal Hospital, Kanazawa, Ishikawa, Japan; ${ }^{3}$ Department of Neurosurgery, Komatsu Municipal Hospital, Kanazawa, Ishikawa, Japan; ${ }^{4}$ Department of Neurosurgery, Ishikawa Prefectural Central Hospital, Kanazawa, Ishikawa, Japan; ${ }^{5}$ Department of Neurosurgery, Asanogawa General Hospital, Kanazawa, Ishikawa, Japan; ${ }^{6}$ Department of Neurosurgery, Kanazawa Neurosurgical Hospital, Nonoichi, Ishikawa, Japan; 'Department of Neurosurgery, Kanazawa Medical Center, Kanazawa, Ishikawa, Japan; ${ }^{8}$ Department of Neurosurgery, Keiju Medical Center, Nanao, Ishikawa, Japan; ${ }^{9}$ Department of Neurosurgery, Noto General Hospital, Nanao, Ishikawa, Japan; ${ }^{10}$ Department of Neurosurgery, Suzu General Hospital, Suzu, Ishikawa, Japan;

${ }^{11}$ Department of Neurosurgery, Toyama Rosai Hospital, Uozu, Toyama, Japan
\end{abstract}

\begin{abstract}
Five recent multicenter randomized controlled trials (RCTs) have clearly shown the superiority of mechanical thrombectomy in large vessel occlusion acute ischemic stroke compared to systemic thrombolysis. Although 14 hospitals in Ishikawa prefecture have uninterrupted availability of systemic thrombolysis, mechanical thrombectomy is not available at all of these hospitals. Therefore, we established a Kanazawa mobile embolectomy team (KMET), which could travel to these hospitals and perform the acute reperfusion therapy. In this article, we report early treatment outcomes and validate the effectiveness of a network between affiliated hospitals and KMET. Between January 2014 and December 2015, 48 patients, aged 45-92 years (mean: 73.0 years), underwent acute reperfusion therapy provided by KMET in 10 affiliated hospitals of Kanazawa University Hospital. The pre-treatment NIHSS scores ranged from 5 to 39 (mean: 19.1). ASPECTS+W ranged from 1 to 11 (mean: 7.3). Successful revascularization, defined as thrombolysis in cerebral infarction (TICI) $2 \mathrm{~b}$ or 3 , was achieved in $38 / 48$ cases (80\%), and a good outcome, defined as modified Rankin Scale (mRS) score from 0 to 2 at 90 days after the treatment, was achieved in $24 / 48$ cases $(50 \%)$. There were two cases of intracranial bleeding $(4 \%)$. Mean time from onset to recanalization was $297 \mathrm{~min}$. These results, which are similar to those of five previous RCTs, suggest that a collaborative network between affiliated hospitals and KMET is effective for acute reperfusion therapy in local areas wherein experienced neuroendovascular specialists are insufficient.
\end{abstract}

Key words: ischemic stroke, embolectomy, recanalization

\section{Introduction}

Recently, five randomized clinical trials of endovascular acute reperfusion therapy against medical treatment have established the benefit of the endovascular treatment in patients with proximal artery occlusions. ${ }^{1-5)}$ All trials have shown a substantial reduction in disability at 90 days after treatment. Based

Received March 28, 2016; Accepted July 26, 2016 on these results, the American Heart Association/ American Stroke Association (AHA/ASA) provided a focused update of the current recommendations for the endovascular treatment of acute ischemic stroke. ${ }^{6)}$ It recommends that the patients who meet the criteria should receive endovascular therapy with a stent retriever.

In Japan, the Japan Stroke Society, the Japan Neurosurgical Society, and the Japanese Society for Neuroendovascular Therapy (JSNET) jointly published 
a guideline concerning the proper use of embolectomy devices for acute ischemic stroke (version 2) in April, 2015. ${ }^{7)}$ It recommends that a specialist certificated by the Specialist Qualification System of the JSNET ${ }^{8)}$ or a physician who has managed at least 100 cases with neuroendovascular treatment should perform the recanalization therapy. Although there are 14 hospitals regarded as primary stroke centers (PSCs), in which there is uninterrupted availability of intravenous rtPA therapy in Ishikawa prefecture, neuroendovascular therapy specialists work full-time in only four hospitals. Therefore, we established a Kanazawa mobile embolectomy team (KMET), which could travel to these hospitals and perform reperfusion therapy. In this article, we report treatment outcomes in the initial stage and validate the effectiveness of a network between affiliated hospitals and KMET.

\section{Materials and Methods}

\section{Organization of KMET}

KMET was organized by two consulting specialists (NU, MM), one specialist (KM), and one fellow (TK) acknowledged by the JSNET in January 2014. All members are board certified Japanese Neurosurgeons who work full-time in the department of Neurosurgery at Kanazawa University Hospital (KUH).

\section{Treatment}

When a stroke patient arrived at an affiliated hospital of KUH, which was thought to be equivalent to a PSC, the physician of first contact in the PSC started intravenous r-tPA therapy if patients were eligible, and call the KMET if the patient met the following criteria, 1) causative occlusion of the internal carotid artery (ICA), middle cerebral artery (MCA), vertebral artery (VA), or basilar artery (BA), 2) Age $\geq 18$ years, 3) NIHSS $\geq 5$, 4) Alberta Stroke Programme Early Computed Tomography Score (ASPECTS) $+\mathrm{W}$ (which is proposed by the ASISTJAPAN; http://assist.umin.jp/) $\geq 5$, and 6) treatment can be initiated (groin puncture) within 6 hours of symptom onset. Two members of the KMET went to the PSC immediately following the call from the PSC. The physician in the PSC obtained informed written consent from the patient or a legal representative before treatment. The physician and KMET then performed acute reperfusion therapy together.

\section{Statistics}

We recorded baseline characteristics, time intervals, and interventional procedural data as well as outcome. In detail this comprised age, sex, pretreatment NIHSS score, ASPECTS+W, site of large vessel occlusion, onset time (or last known normal time), patient arrival time, time of MRI, time of the call to KMET, when iv-rtPA was started, time of groin puncture and recanalization, type of reperfusion treatment and devices, result of recanalization (thrombolysis in cerebral infarction: TICI), and disability (modified Rankin Scale: mRS) at 90 days following treatment. The data are expressed as means unless indicated otherwise.

The patients were divided by the mRS score into the good outcome group (mRS score from 0 to 2 ) or the poor outcome one (mRS score from 3 to 6). Various time intervals were compared between the two groups using Student's $t$ test. The cause of stroke, site of vessel occlusion, TICI grade, and distance from KUH to the PSC were compared between the two groups using chi-square test. Additionally, the patients were divided by onset to recanalization (O2R) time into three groups-less than $4 \mathrm{~h}$, from 4 to $5 \mathrm{~h}$, and above $5 \mathrm{~h}$. The proportion of the patients with good outcome were compared between the three groups using Kruskal-Wallis test. Odds ratios (ORs) of good outcome with corresponding $95 \%$ confidence intervals (CIs) were calculated by using univariate and multivariate logistic regression for the following four clinical characteristics: NIHSS $<20$, ASPECTS $+W \geq 8$, onset to recanalization $<240$ min, and TICI $2 b$ or 3 .

Standard statistical tests [Student's $t$ test, chisquare test, and the Kruskal-Wallis test (for nonparametric data)] were applied when applicable. Logistic regression was used for univariate and multivariate analyses. $\mathrm{P}$ values less than or equal to the $\alpha$ level of 0.05 were considered significant. All statistical analyses were performed using SPSS 20 software (IBM, Armonk, NY, USA).

\section{Results}

Between January 2014 and December 2015, 48 patients underwent acute reperfusion therapy provided by KMET for acute ischemic stroke in 10 affiliated hospitals of KUH. Ishikawa Prefectural Central Hospital, Kanazawa Municipal Hospital, Kanazawa Medical Center, Asanogawa General Hospital, and Kanazawa Neurosurgical Hospital in Ishikawa central medical district are located within $20 \mathrm{~km}$ of KUH. Komatsu Municipal Hospital in South Kaga medical district, Keiju Medical Center and Noto General Hospital in Middle Noto medical district are located between 20 and $80 \mathrm{~km}$ from KUH. Suzu General Hospital in North Noto medical district and Toyama Rosai Hospital in Toyama prefecture are further than $80 \mathrm{~km}$ from KUH (Fig. 1). These hospitals function as PSCs in Ishikawa and Toyama prefecture.

Patient characteristics are summarized in Table 1. The patients were 36 males and 12 females, aged 


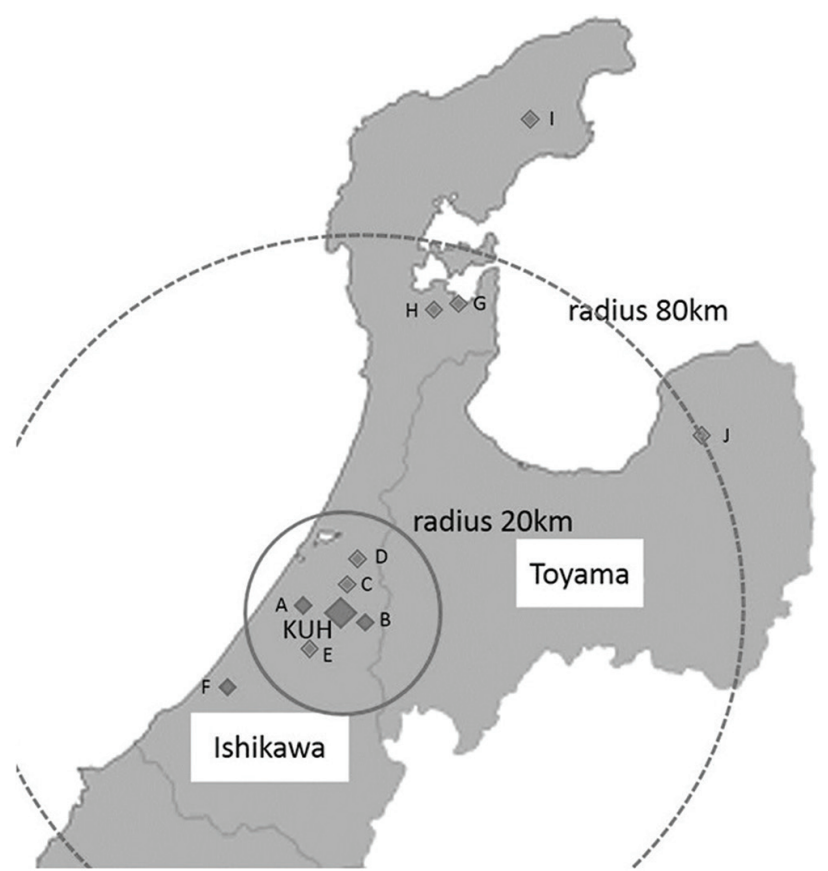

Fig. 1 Kanazawa University Hospital and the affiliated hospitals in Ishikawa and Toyama prefectures. Circles of solid and dotted lines indicate 20 and $80 \mathrm{~km}$ from Kanazawa University Hospitals, respectively. A: Ishikawa Prefectural Central Hospital, B: Kanazawa Municipal Hospital, C: Kanazawa Medical Center, D: Asanogawa General Hospital, E: Kanazawa Neurosurgical Hospital, F: Komatsu Municipal Hospital, G: Keiju Medical Center, H: Noto General Hospital I: Suzu General Hospital, and J: Toyama Rosai Hospital.

Table 1 Patient characteristics

\begin{tabular}{lc}
\hline Patient no. & 48 \\
Age (mean \pm SD) & $73.0 \pm 8.9$ \\
Male sex no. (\%) & $36(75)$ \\
NIHSS (mean \pm SD) & $19.1 \pm 7.8$ \\
ASPECTS+W (mean \pm SD) & $7.3 \pm 2.4$ \\
Cause of stroke - no. (\%) & \\
$\quad$ Cardioembolic occlusion & $38(79)$ \\
$\quad$ Atherothrombotic occlusion & $8(17)$ \\
$\quad$ Dissection & $2(4)$ \\
Site of vessel occlusion - no. (\%) & \\
Internal carotid artery & $22(46)$ \\
Proximal middle cerebral artery & $11(23)$ \\
$\quad$ Distal middle cerebral artery & $8(17)$ \\
Vertebral artery & $1(2)$ \\
Basilar artery & $6(12)$
\end{tabular}

ASPECTS: Alberta Stroke Program Early Computed Tomography Score, NIHSS: National Institutes of Health Stroke Scale.

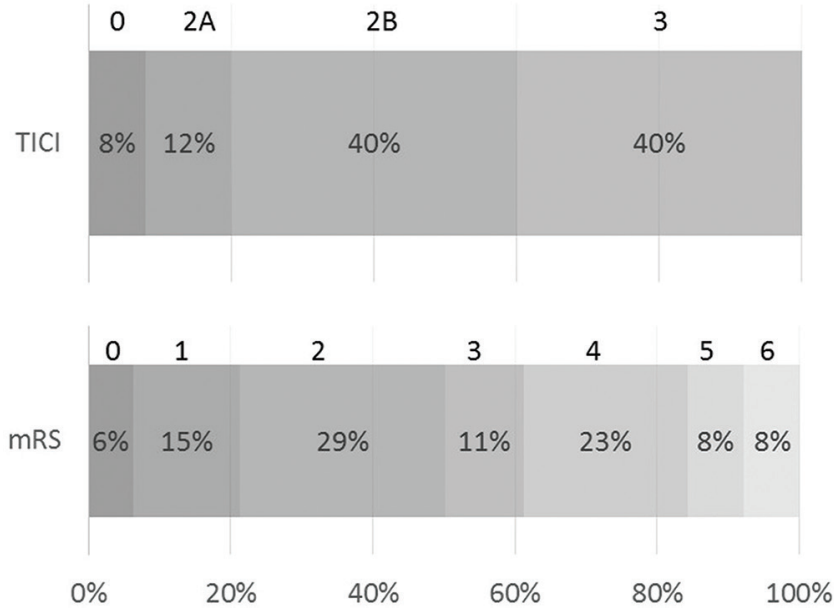

Fig. 2 Grading of Thrombolysis in Cerebral Infarction (TICI) and score on Modified Rankin Scale (mRS) at 90 days after treatment.

45 to 92 years (mean: 73.0 years). Sites of occlusion included the ICA in 22 patients, proximal MCA in 11 patients, distal MCA in eight patients, VA in one patient, and BA in six patients. Pre-treatment NIHSS score ranged from 5 to 39 (mean: 19.1). ASPECTS+W ranged from 1 to 11 (mean: 7.3). Three patients underwent carotid artery stenting (CAS) for atherothrombotic occlusion of the ICA. All but the three patients received mechanical thrombectomy. Devices used in this study included the Penumbra system (Penumbra Inc., Alameda, CA, USA) in 19 patients, the Trevo ProVue Retriever (Stryker Neurovascular, Fremont, CA, USA) in 13 patients, Merci (Stryker Neurovascular, Fremont, CA, USA) in one patient and a combination of the Penumbra system and the Trevo ProVue Retriever in 12 patients.

Overall successful revascularization, defined as TICI $2 \mathrm{~b}$ or 3 , was achieved in $38 / 48$ patients $(80 \%)$, and a good outcome, defined as mRS score from 0 to 2 , was achieved in $24 / 48$ patients (50\%) (Fig. 2). There were two cases of intracranial bleeding (4\%). The bleeding was caused by vessel perforation in one case, and hemorrhagic transformation in the other case. The former was symptomatic. The overall mortality rate at 90 days was $8 \%(4 / 48)$.

Mean time from onset to patient arrival was 67 min, mean time from hospital arrival to MRI was 62 min, mean time from MRI to calling the KMET was $35 \mathrm{~min}$, mean time from the call to the KMET to iv-rtPA was $2 \mathrm{~min}$, mean time from iv-rtPA to groin puncture was $58 \mathrm{~min}$, mean time from groin puncture to recanalization was $73 \mathrm{~min}$, and mean time from onset to recanalization was $297 \mathrm{~min}$ (Fig. 3). Comparison of characteristics between good and poor outcome groups are summarized in 


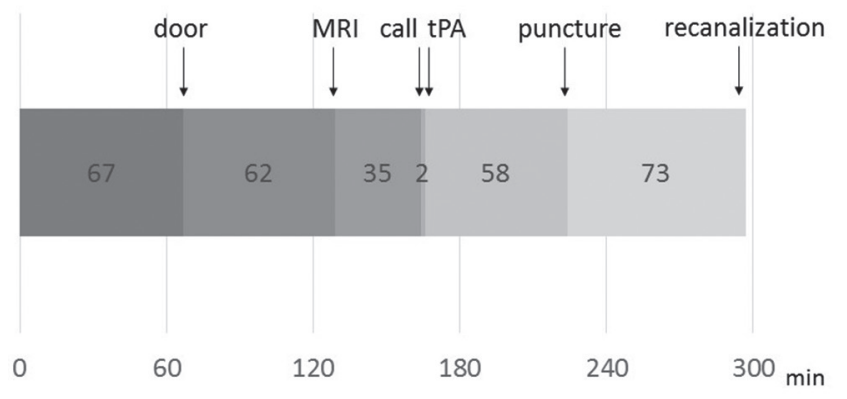

Fig. 3 Mean time course of all patients in the acute recanalization therapy. call: the time to call KMET (Kanazawa mobile embolectomy team).

Table 2. Pre-treatment NIHSS score, ASPECT $+\mathrm{W}$, TICI grade were significantly different between the two groups. Mean time from onset to recanalization of the good outcome and poor outcome groups were $291 \mathrm{~min}$ and $304 \mathrm{~min}$, respectively, which were not significantly different. Various time intervals other than puncture to recanalization were not significantly different.

The relationship between rates of good outcome and $\mathrm{O} 2 \mathrm{R}$ time is shown in Table 3 . When O2R was less than $4 \mathrm{~h}$, there was a good outcome $62 \%$ in all patients. It decreased to $42 \%$, when $\mathrm{O} 2 \mathrm{R}$ was from 4 to $5 \mathrm{~h}$. However, it increased again to $50 \%$, when $\mathrm{O} 2 \mathrm{R}$ was more than $5 \mathrm{~h}$. As analyzed by cause of stroke, the rate of good outcome in the 38 patients with cardioembolic occlusion (CEO) gradually decreased as O2R time increased $(58 \% \rightarrow 47 \% \rightarrow 36 \%)$, although it was not statistically significant. On the other hand, there was no relationship between the rate of eight patients with atherothrombotic occlusion (ATO) and the time course $(100 \% \rightarrow 33 \% \rightarrow 100 \%)$.

The relative contribution of different variables to good outcome at 90 days is shown in Table 4. On univariate analysis, baseline NIHSS score $<20$, ASPECTS $+W \geq 8$, and TICI $2 b$ or 3 were significantly associated with a good outcome at 90 days. The multivariate logistic regression analysis identified ASPECTS $+\mathrm{W} \geq 8$ (OR, 4.46; 95\% CI, 1.116-17.82, $\mathrm{p}=0.0344)$, and TICI $2 \mathrm{~b}$ or 3 (OR, 8.204; 95\% CI, $1.146-58.71, p=0.0361$ ) as independent factors for a good outcome at 90 days.

\section{Discussion}

The rate of revascularization in our study was $80 \%$, similar to five previously published randomized controlled trials (RCTs), ranging from $59 \%$ in MR CLEAN to $86 \%$ in EXTEND-IA and $88 \%$ in SWIFT PRIME. ${ }^{1-5)}$ The good outcome rate, defined as mRS 0-2 at 90 days after treatment, was $50 \%$, again similar to the RCTs, ranging from $33 \%$ in MR CLEAN to $71 \%$ in EXTEND-IA (Table 5). ${ }^{1-5)}$ These results indicate that acute recanalization therapy of the KMET can be safely applied under real-world conditions in our local area.

Although improved clinical outcomes are observed with decreased time to reperfusion in general, there was no significant difference in the total time course between the good outcome group and the poor outcome one in our study. Only time from puncture to recanalization in the poor outcome group was significantly longer than that in the good outcome one, because it took more time for refractory cases in which occluded vessels could not be opened in the poor outcome group. In patients with CEO, the greater the time to reperfusion extended, the lower the better outcome rate decreased. On the other hand, all patients with ATO achieved a good outcome, even if the time to reperfusion was more than $5 \mathrm{~h}$. Most cases of ATO have better collateral flow compare to CEO, in particular in cases of vertebrobasilar occlusion. ${ }^{9)}$ In fact, three cases of atherothrombotic basilar occlusion in this study, whose time from onset to recanalization was 280-666 min, had a good outcome. The relatively high proportion of such patients with ATO $(22 \%)$ in our study might make the relationship between the time course and the outcome obscure.

Time from onset to groin puncture is one of the most important time-interval metrics. The mean and median time from onset to groin puncture in our study were 224 and 205 min, respectively. Though it took about $60-70 \mathrm{~min}$ for the KMET to reach the affiliated hospitals, the median time of $205 \mathrm{~min}$ is similar to those in the five published RCTs, ranging from $200 \mathrm{~min}$ in ESCAPE to 269 min in REVASCAT (Table 5). This result suggests that the treatment system of a mobile embolectomy team does not extend the total time of the recanalization therapy. Furthermore, we may reduce time to revascularization. Mean time from patient arrival to MRI and to groin puncture in our study were 67 and $157 \mathrm{~min}, 42$ and 37 min longer than the recommended time, ${ }^{10)}$ respectively. We will be able to reduce the door-to-imaging (MRI) time after carefully investigating workflow in the PSC. In addition, physicians in the PSC should call the KMET immediately after learning of large vessel occlusion on MRI. The sooner the KMET depart to the affiliated hospital, the earlier the endovascular treatment can start. Reduction of the total time from onset to recanalization can increase the rate of patients with favorable outcome. ${ }^{11)}$

In our study, relatively small ischemic lesions (ASPECTS $+\mathrm{W} \geq 8$ ) and good recanalization (TICI 
Table 2 Comparison of characteristics between good and poor outcome groups

\begin{tabular}{|c|c|c|c|}
\hline & Good outcome & Poor outcome & $\mathrm{p}$ \\
\hline Patient no. & 24 & 24 & \\
\hline Age (mean \pm SD) & $73.3 \pm 8.1$ & $72.8 \pm 9.9$ & 0.8484 \\
\hline Male sex no. (\%) & $21(88)$ & $15(63)$ & 0.0956 \\
\hline NIHSS (mean \pm SD) & $16.0 \pm 7.4$ & $22.2 \pm 7.1$ & 0.0051 \\
\hline ASPECTS+W (mean \pm SD) & $8.4 \pm 4.1$ & $6.3 \pm 2.2$ & 0.001 \\
\hline Cause of stroke - no. (\%) & & & 0.1284 \\
\hline Cardioembolic occlusion & $18(75)$ & $20(84)$ & \\
\hline Atherothrombotic occlusion & $6(25)$ & $2(8)$ & \\
\hline Dissection & $0(0)$ & $2(8)$ & \\
\hline Site of vessel occlusion - no. (\%) & & & 0.5334 \\
\hline Internal carotid artery & $9(37)$ & $13(54)$ & \\
\hline Proximal middle cerebral artery & $6(25)$ & $5(21)$ & \\
\hline Distal middle cerebral artery & $4(17)$ & $4(17)$ & \\
\hline Vertebral artery & $1(4)$ & $0(0)$ & \\
\hline Basilar artery & $4(17)$ & $2(8)$ & \\
\hline Iv-rtPA & $11(46)$ & $13(54)$ & 0.7732 \\
\hline TICI - no. (\%) & & & 0.0244 \\
\hline 0 & $0(0)$ & $4(17)$ & \\
\hline 1 & $0(0)$ & $0(0)$ & \\
\hline $2 \mathrm{~A}$ & $2(8)$ & $4(17)$ & \\
\hline $2 \mathrm{~B}$ & $8(33)$ & $11(46)$ & \\
\hline 3 & $14(59)$ & $5(20)$ & \\
\hline \multicolumn{4}{|l|}{ Time course - minutes (mean \pm SD) } \\
\hline LKN to door & $70.4 \pm 69.1$ & $64.3 \pm 67.6$ & 0.7609 \\
\hline Door to picture (MRI) & $67.0 \pm 30.7$ & $57.7 \pm 30.4$ & 0.2958 \\
\hline Door to call KMET & $101.0 \pm 104.9$ & $93.3 \pm 51.0$ & 0.7502 \\
\hline Door to puncture & $159.4 \pm 103.4$ & $152.8 \pm 43.5$ & 0.775 \\
\hline Puncture to recanalization & $62.3 \pm 25.5$ & $83.8 \pm 34.1$ & 0.0175 \\
\hline LKN to needle (iv-rtPA) & $149.6 \pm 41.7$ & $157.6 \pm 45.6$ & 0.6612 \\
\hline LKN to puncture & $228.1 \pm 110.2$ & $220.0 \pm 75.3$ & 0.7691 \\
\hline LKN to recanalization & $290.9 \pm 109.9$ & $303.8 \pm 88.5$ & 0.6548 \\
\hline Distance from KUH - no. (\%) & & & 0.083 \\
\hline$\leq 20 \mathrm{~km}$ & $16(67)$ & $9(38)$ & \\
\hline$>20 \mathrm{~km}$ & $8(33)$ & $15(62)$ & \\
\hline
\end{tabular}

ASPECTS: Alberta Stroke Program Early Computed Tomography Score, TICI: thrombolysis in cerebral infarction, LKN: last known normal, KUH: Kanazawa University Hospital, KMET: Kanazawa mobile embolectomy team.

$2 \mathrm{~b}$ or 3) were factors significantly associated with a 90-day good outcome. These results are consistent with the previous reports. ${ }^{12)}$ We treated the 10 patients with an ASPECTS+W score less than 6. Although all but one patient could not independently perform activities of daily living, conventional conservative therapy alone may worsen their prognosis. As indicated by the AHA/ ASA guidelines, the endovascular recanalization therapy may be reasonable for patients with a low ASPECTS score, if the treatment can be initiated within $6 \mathrm{~h}$ of symptom onset. ${ }^{6)}$

In summary, total time course and treatment results of acute reperfusion therapy provided by KMET were almost the same as those reported in five recently published RCTs. Our findings suggest that a collaborative network between affiliated hospitals and KMET is effective for acute 
Table 3 Relationship between onset to recanalization (O2R) time and good outcome rate

\begin{tabular}{llcccc}
\hline & O2R & $<4 \mathrm{~h}$ & $4-5 \mathrm{~h}$ & $5 \mathrm{~h}<$ & P value \\
\hline CEO & patient no. & 12 & 15 & 11 & 0.5773 \\
& mRS 0-2 & 7 & 7 & 4 & 0.3292 \\
\multirow{2}{*}{ ATO } & good outcome rate & $58 \%$ & $47 \%$ & $36 \%$ & \\
& patient no. & 1 & 3 & 4 & $100 \%$ \\
& mRS 0-2 & 1 & 1 & 16 & 0.6516 \\
& good outcome rate & $100 \%$ & 19 & 8 & $50 \%$ \\
\end{tabular}

ATO: atherothrombotic occlusion, CEO: cardioembolic occlusion, mRS: modified Rankin Scale.

Table 4 Results of possible factors for a good outcome after acute recanalization therapy using univariate logistic regression analysis

\begin{tabular}{lcccc}
\hline Variables & $\mathrm{n}$ & Odds ratio & 95\% CI (min-max) & $\mathrm{p}$ \\
\hline NIHSS $\leq 20$ & 26 & 4.0 & $1.210-13.539$ & 0.0232 \\
ASPECT $+\mathrm{W} \geq 8$ & 26 & 6.0 & $1.711-21.040$ & 0.0051 \\
Onset to recanalization $\leq 240$ min & 13 & 1.9 & $0.518-6.975$ & 0.4175 \\
TICI 2B \& 3 & 38 & 5.5 & $1.027-29.456$ & 0.0465 \\
\hline
\end{tabular}

ASPECTS: Alberta Stroke Program Early Computed Tomography Score, NIHSS: National Institutes of Health Stroke Scale, TICI: thrombolysis in cerebral infarction.

Table 5 Summary of results of the present study and recent randomized control trials in endovascular thrombectomy for ischemic stroke

\begin{tabular}{|c|c|c|c|c|c|}
\hline & $\mathrm{n}$ & $\begin{array}{l}\text { Median onset-to-groin } \\
\text { puncture time (min) }\end{array}$ & TICI $2 \mathrm{~b}$ or 3 & $\begin{array}{l}\text { mRS 0-2 } \\
\text { at } 90 \text { days }\end{array}$ & $\begin{array}{l}\text { Mortality } \\
\text { at } 90 \text { days }\end{array}$ \\
\hline MR CLEAN & 233 & 260 & $59 \%$ & $33 \%$ & $21 \%$ \\
\hline EXTEND IA & 35 & 210 & $86 \%$ & $71 \%$ & $9 \%$ \\
\hline ESCAPE & 165 & 200 & $72 \%$ & $53 \%$ & $10 \%$ \\
\hline SWIFT PRIME & 98 & 224 & $88 \%$ & $60 \%$ & $9 \%$ \\
\hline REVASCAT & 103 & 269 & $66 \%$ & $44 \%$ & $18 \%$ \\
\hline KMET & 48 & 205 & $80 \%$ & $50 \%$ & $8 \%$ \\
\hline
\end{tabular}

mRS: modified Rankin Scale, TICI: thrombolysis in cerebral infarction.

reperfusion therapy in a local area wherein experienced neuroendovascular specialists are insufficient.

\section{Acknowledgments}

We express our sincere thanks to all of directors of departments of Neurosurgery in affiliated hospitals for their cooperation to our study; Ryuichi Kitani \& Yoshio Nakajima (Toyama Rosai Hospital), Hiroaki
Onishi (Asanogawa General Hospital), Sotaro Higashi \& Yosie Okada (Keiju Medical Center), Masato Ikeda \& Hiroki Sano (Kanazawa Municipal Hospital), Yutaka Hayashi (Ishikawa Prefectural Central Hospital), Hironori Fujisawa \& Shuichi Akaike (Kanazawa Medical Center), Hisashi Nitta \& Takuya Watanabe (Komatsu Municipal Hospital), Cheho Park (Noto General Hospital), and Shuji Satoh \& Jiro Yamamoto (Kanazawa Neurosurgical Hospital). 
This study was partially funded by grants from the Japan Agency for Medical Research and Development, AMED.

\section{Conflicts of Interest Disclosure}

The authors have no personal, financial, or institutional interest in any of the drugs, materials, or devices in the article. All authors who are members of The Japan Neurological Society (JNS) have registered online Self-reported COI Disclosure Statement Forms through the website for JNS members.

\section{References}

1) Berkhemer OA, Fransen PS, Beumer D, van den Berg LA, Lingsma HF, Yoo AJ, Schonewille WJ, Vos JA, Nederkoorn PJ, Wermer MJ, van Walderveen MA, Staals J, Hofmeijer J, van Oostayen JA, Lycklama à Nijeholt GJ, Boiten J, Brouwer PA, Emmer BJ, de Bruijn SF, van Dijk LC, Kappelle LJ, Lo RH, van Dijk EJ, de Vries J, de Kort PL, van Rooij WJ, van den Berg JS, van Hasselt BA, Aerden LA, Dallinga RJ, Visser MC, Bot JC, Vroomen PC, Eshghi O, Schreuder TH, Heijboer RJ, Keizer K, Tielbeek AV, den Hertog HM, Gerrits DG, van den Berg-Vos RM, Karas GB, Steyerberg EW, Flach HZ, Marquering HA, Sprengers ME, Jenniskens SF, Beenen LF, van den Berg R, Koudstaal PJ, van Zwam WH, Roos YB, van der Lugt A, van Oostenbrugge RJ, Majoie CB, Dippel DW, MR CLEAN Investigators: A randomized trial of intraarterial treatment for acute ischemic stroke. N Engl J Med 372: 11-20, 2015

2) Campbell BC, Mitchell PJ, Kleinig TJ, Dewey HM, Churilov L, Yassi N, Yan B, Dowling RJ, Parsons MW, Oxley TJ, Wu TY, Brooks M, Simpson MA, Miteff F, Levi CR, Krause M, Harrington TJ, Faulder KC, Steinfort BS, Priglinger M, Ang T, Scroop R, Barber PA, McGuinness B, Wijeratne T, Phan TG, Chong W, Chandra RV, Bladin CF, Badve M, Rice H, de Villiers L, Ma H, Desmond PM, Donnan GA, Davis SM, EXTEND-IA Investigators: Endovascular therapy for ischemic stroke with perfusion-imaging selection. N Engl J Med 372: 1009-1018, 2015

3) Goyal M, Demchuk AM, Menon BK, Eesa M, Rempel JL, Thornton J, Roy D, Jovin TG, Willinsky RA, Sapkota BL, Dowlatshahi D, Frei DF, Kamal NR, Montanera WJ, Poppe AY, Ryckborst KJ, Silver FL, Shuaib A, Tampieri D, Williams D, Bang OY, Baxter BW, Burns PA, Choe H, Heo JH, Holmstedt CA, Jankowitz B, Kelly M, Linares G, Mandzia JL, Shankar J, Sohn SI, Swartz RH, Barber PA, Coutts SB, Smith EE, Morrish WF, Weill A, Subramaniam S, Mitha AP, Wong JH, Lowerison MW, Sajobi TT, Hill MD, ESCAPE Trial Investigators: Randomized assessment of rapid endovascular treatment of ischemic stroke. N Engl J Med 372: 1019-1030, 2015
4) Saver JL, Goyal M, Bonafe A, Diener HC, Levy EI, Pereira VM, Albers GW, Cognard C, Cohen DJ, Hacke W, Jansen O, Jovin TG, Mattle HP, Nogueira RG, Siddiqui AH, Yavagal DR, Baxter BW, Devlin TG, Lopes DK, Reddy VK, du Mesnil de Rochemont R, Singer OC, Jahan R, SWIFT PRIME Investigators: Stent-retriever thrombectomy after intravenous t-PA vs. t-PA alone in stroke. $N$ Engl J Med 372: 2285-2295, 2015

5) Jovin TG, Chamorro A, Cobo E, de Miquel MA, Molina CA, Rovira A, San Román L, Serena J, Abilleira S, Ribó M, Millán M, Urra X, Cardona P, López-Cancio E, Tomasello A, Castaño C, Blasco J, Aja L, Dorado L, Quesada H, Rubiera M, Hernandez-Pérez M, Goyal M, Demchuk AM, von Kummer R, Gallofré M, Dávalos A, REVASCAT Trial Investigators: Thrombectomy within 8 hours after symptom onset in ischemic stroke. $N$ Engl $J$ Med 372: 2296-2306, 2015

6) Powers WJ, Derdeyn CP, Biller J, Coffey CS, Hoh BL, Jauch EC, Johnston KC, Johnston SC, Khalessi AA, Kidwell CS, Meschia JF, Ovbiagele B, Yavagal DR, American Heart Association Stroke Council: 2015 American Heart Association/American Stroke Association Focused Update of the 2013 Guidelines for the Early Management of Patients With Acute Ischemic Stroke Regarding Endovascular Treatment: A Guideline for Healthcare Professionals From the American Heart Association/American Stroke Association. Stroke 46: 3020-3035, 2015

7) The Japan Stroke Society, the Japan Neurosurgical Society, and the Japanese Society for Neuroendovascular Therapy: Guideline of proper use of embolectomy devices for acute ischemic stroke (version 2) http://www.jsts.gr.jp/img/noukessen.pdf

8) Hyogo T, Taki W, Negoro M, Takahashi A, Edura M, Hyodo A, Kobayashi S, Komiyama M, Kuwayama N, Matsumaru Y, Miyachi S, Murao K, Murayama Y, Nakahara I, Nemoto S, Sakai N, Satoh K, Sonobe M, Sugiu K, Terada T, Yoshimura S, Abe T, Itoh Y, Kiyosue H, Nagashima H, Nakamura M, Matsushima $S$, Japanese society of neuro-endovascular treatment specialist qualification system. Six years' experience and introduction of an animal model examination. Interv Neuroradiol 14: 235-240, 2008

9) Cross DT, 3rd, Moran CJ, Akins PT, Angtuaco EE, Derdeyn CP, Diringer MN: Collateral circulation and outcome after basilar artery thrombolysis. AJNR Am J Neuroradiol 19: 1557-1563, 1998

10) Sacks D, Black CM, Cognard C, Connors JJ 3rd, Frei D, Gupta R, Jovin TG, Kluck B, Meyers PM, Murphy KJ, Ramee S, Rüfenacht DA, Bernadette Stallmeyer MJ, Vorwerk D, American Society of Neuroradiology; Canadian Interventional Radiology Association; Cardiovascular and Interventional Radiological Society of Europe; Society for Cardiovascular Angiography and Interventions; Society of Interventional Radiology; Society of NeuroInterventional Surgery; European Society of Minimally Invasive 
Neurological Therapy; Society of Vascular and Interventional Neurology. Multisociety Consensus Quality Improvement Guidelines for Intraarterial Catheterdirected Treatment of Acute Ischemic Stroke, from the American Society of Neuroradiology, Canadian Interventional Radiology Association, Cardiovascular and Interventional Radiological Society of Europe, Society for Cardiovascular Angiography and Interventions, Society of Interventional Radiology, Society of NeuroInterventional Surgery, European Society of Minimally Invasive Neurological Therapy, and Society of Vascular and Interventional Neurology. J Vasc Interv Radiol 24: 151-63, 2013

11) Khatri P, Abruzzo T, Yeatts SD, Nichols C, Broderick JP, Tomsick TA, IMS I and II Investigators: Good clinical outcome after ischemic stroke with successful revascularization is time-dependent. Neurology 73: 1066-1072, 2009

12) Prabhakaran S, Ruff I, Bernstein RA: Acute stroke intervention: a systematic review. JAMA 313: 1451-62, 2015

Address reprint requests to: Naoyuki Uchiyama, $\mathrm{MD}, \mathrm{PhD}$, Department of Neurosurgery, Kanazawa University Hospital, 13-1 Takaramachi, Kanazawa, Ishikawa 920-8641, Japan. Tel: +81-76-265-2384; Fax +81-76234-4262.

e-mail: naoyuki.uchiyama@med.kanazawa-u.ac.jp 